\title{
Global Macroeconomic Performance: A Comparative Study Based on Composite Scores
}

\author{
Somnath Chattopadhyay,"\# and Suchismita Bose ${ }^{\#}$
}

\author{
Monetary Research Project, ICRA Limited
}

\begin{abstract}
This paper proposes a composite indicator designed to summarise in a single statistic a variety of different facets of macroeconomic performance and assesses relative performances of countries with respect to six macroeconomic variables, viz., the growth rate of real GDP, real per capita GDP, unemployment rate, fiscal balance, rate of inflation, and current account balance. An appropriate mathematical model to aggregate these variables to form composite scores has been implemented by adopting the MCDM (Multiple Criteria Decision Making) technique of TOPSIS (Technique for Order Preference by Similarity to Ideal Solution). This allows a parsimonious representation of a variety of different facets of macroeconomic performance and its inter-temporal comparison across countries. The distinctive features of the indicator relate to the domains covered, the normalisation methodology and the weights used for aggregation. Some existing indices like the Okun index and the Calmfors index turn out to be special cases of our proposed index. The data comprising a wide spectrum of countries and spanning the pre- and post- crisis years allow us to capture the effect of the recent global financial and economic crisis on the overall macroeconomic performance of countries relative to others. Not only do the relative performance scores show tremendous variability during the postcrisis years, but the measures of disarray are also at their highest, despite there being overall stability in the country rankings in terms of indicators, which are traditionally relied on, like GDP growth or per-capita GDP. A single graphical plot easily identifies countries that have performed consistently over time, and those whose overall macroeconomic performances have deteriorated sharply relative to others during the post-crisis years.
\end{abstract}

Keywords: Macroeconomic Performance, Correspondence Analysis, Composite Scores, Country Rankings, Measures of Disarray, TOPSIS, Entropy.

\section{INTRODUCTION}

Macroeconomic policy of governments is generally committed to the three goals of growth, employment creation and price stability. These goals are explicitly stated in the US Employment Act of 1946. The European Union's Stability and Growth Pact, also for instance, proclaims sound government finances as a means to strengthening the conditions for price stability and for strong and sustainable growth conducive to employment creation. The same three policy goals have been stated earlier in national legislations, e.g., the 1967 German 'Stabilitats und Wachstumsgesetz' (Law on Stability and Growth); this law contains, in addition, the goal of balance of payment equilibrium (Welsch 2011). While there are marked differences in the planned efforts countries make in achieving these objectives there are also substantial variations among the countries in the performance on each objective. There is thus widespread interest in measuring and comparing the economic performance of countries to gauge the success of the individual macroeconomic policies followed by each one. Traditionally, the macroeconomic performance of a nation is measured as the extent to which these policy goals are realised

\footnotetext{
${ }^{*}$ Address correspondence to this author at Economist, Monetary Research Project, ICRA Ltd., B 245 Lake Gardens, Ground Floor, Kolkata 700045, West Bengal, India; Fax: +91-33-40072195; E-mail: pikluchatterjee@gmail.com

"Formerly affiliated to Indian Statistical Institute, Kolkata.

JEL Codes: C4; 057.
}

(Crockett and Goldstein 1987); the same are summarised conventionally in terms of an array of carefully chosen indicators. The approach has sometimes been called "constructing a "dashboard" of indicators' (Stiglitz and Sen 2009). The most important or oft-quoted indicators within the dashboard are growth, inflation, unemployment, as also the balances on the government account and the external account of the economy.

While there is the undisputed need to consider all indicators relating to the different aspects of policymaking, the usefulness of a composite indicator, capturing all these aspects together, cannot be denied either. This is particularly so as policies pursuing the different macroeconomic goals of growth, employment, and price stability usually involve certain trade-offs; ${ }^{1}$ these three have thus been dubbed as the "magic triangle" of economics (Welsch 2011). Policies, which aim at augmenting growth, are also known, because of increased imports, to lead to current account imbalances, at least until the supply side factors adjust accordingly. Thus, the Organisation for Economic Cooperation and Development (OECD) captures the macroeconomic performance of an economy using four

\footnotetext{
${ }^{1}$ For instance, the Phillips curve implies that price stability comes at a cost in terms of unemployment. On the other hand, any growth and employment enhancing policies are usually demand generating, and hence may be inflationary.
}

(C) 2015 Lifescience Global 
dimensions, namely real growth, inflation, unemployment, and the external account, which are envisaged by the "magic diamond" of the OECD. However, measures such as these are not easy to comprehend or compare. Furthermore, these measures are noncommittal about the weight to be attached to each indicator while judging the overall economic trend or performance. In fact the usefulness of any composite indicator is contingent upon the manner in which the incommensurability among different attributes is addressed and appropriate weights are assigned to each attribute. In practice, attributes are often weighted equally, or instead, results from polls or surveys are used; in latter case, though, the weighting may be inappropriate and subjective. No matter how strong macroeconomic tradeoffs actually are, it is evident that to pursue a multi-dimensional goal system and evaluate the success of the respective policies requires an appropriate weighting of the constituent goals. ${ }^{2}$

In this paper we take the composite indicators approach that consists in aggregating several variables to encompass a broad spectrum of dimensions affecting macroeconomic performances of nations. ${ }^{3}$ We present a composite measure, which merges separate indicators of macroeconomic policy outcomes using the techniques of "Multiple Criteria Decision Making" (MCDM), and is capable of containing the relevant information about the overall economic performance of an economy in one single statistic ${ }^{4}$. The methodological build up of the paper is three-pronged. The introduction gives the theoretical justification of the selection of variables in constructing a macroperformance function. This is essentially based on the dashboard of indicators used in the literature to track

\footnotetext{
${ }^{2} \mathrm{~A}$ theoretical construct that represents such a weighting is a macroeconomic social welfare function W (unemployment, inflation) proposed by (Barro and Gordon 1983) and now a standard device in macroeconomic textbooks ((Blanchard and Fischer 1989); (Burda and Wyplosz 1993); (Hall and Taylor 1997)). However, lacking an empirical equivalent to this construct, one could hardly do better than simply relying on the sum of the unemployment and inflation rates (misery index) (Okun 1978) as an approximation.

${ }^{3}$ Composite indicators have been increasingly used for performance monitoring, benchmarking, policy analysis, and public communication in wide ranging fields including the economy. The most well-known composite indicator is the Human Development Index (HDI) proposed by the United Nation Development Programme (UNDP) in 1990. To balance comparisons between countries based on GDP per capita in PPP (purchasing power parities), the UNDP extended the analysis to health and educational achievement, regarded as two major ingredients of development and progress.

${ }^{4} \mathrm{MCDM}$ is a decision-making method which is most appropriate where a solution to a particular problem requires satisfying a number of different parties and reconciling multiple and often conflicting objectives. It is a sub-discipline of "Operations Research" (OR) that explicitly considers multiple criteria in decision-making environments and is extensively used in a wide variety of planning processes such as project management, financial, environmental or socio-economic planning.
}

the various aspects of macroeconomic performance. ${ }^{5}$ The second step is contingent upon building an appropriate mathematical model to aggregate these variables to form composite scores, which has been implemented by adopting the technique of MCDM. The MCDM technique used in this paper is TOPSIS (Technique for Order Preference by Similarity to Ideal Solution), which has a definite edge over the others. In this, an ideal solution with respect to each policy variable is formulated. This is based on the premises that the best alternative would be the one which has the shortest distance from the ideal solution and the farthest distance from the non-ideal, i.e., the worst, solution. The performance of any country is then measured in terms of its relative position in reference to these two points. A country having the best values of all the attributes is supposed to have a performance score of one as against the zero score of a country having the worst values of all the attributes, the scores for the intermediate cases obviously lying in between.

Once the year-wise performance scores are computed, we apply statistical tests to assess the positional changes in the Top-k relative rankings over time. For an overall assessment of the (year-wise) rankings, we apply the technique of Correspondence Analysis (CA) (Greenacre 1984) onto the data matrix containing the (status of) rankings of countries (over the years). In absence of any a priori hypotheses, though, about relations between variables (as in traditional hypothesis testing), we resort to the exploratory data analysis for identifying systematic relations, if any, between the variables (status of ranking and list of countries) by this technique. ${ }^{6}$ The joint graphical display obtained from CA reveals the spatial association between the said variables. The data in this paper spans the pre- and post- crisis periods when governments across the world face severe challenges of macroeconomic policymaking.

The layout of the paper is as follows. Section 1 provides the justification for the composite indicator approach for ranking macroeconomic performance of

\footnotetext{
${ }^{5}$ See, for example (Welsch 2011), (Moesen and Cherchye 1998), (Stiglitz and Sen 2009).

${ }^{6}$ Essentially CA contains three basic concepts: one, a point in multidimensional space; two, a weight (or mass) assigned to each point; and three, a distance function between the points, called the chi-squared distance. With these three concepts defined, the method tries to reduce the dimensionality of the points by projecting them onto a subspace, usually a two-dimensional plane, as mentioned above. This subspace optimally fits the points by the method of weighted least squares -- a method where each point is weighted by its respective mass, and measurement of distance between points and the subspace is done in terms of chi-squared distance (Greenacre 2002).
} 
countries across the globe and for the MCDM framework chosen here to arrive at a composite indicator of macroeconomic performance. Section 2 presents the methodological framework for the construction of the indicator, the rankings based on the performance scores and temporal comparison of rankings. Section 3 presents the data with which the composite indicator has been constructed for this study and the results from the analysis of the performance scores of a number of countries. ${ }^{7}$ Section 4 presents a summary of the methodology and a concluding note.

\section{METHODOLOGY}

The macroeconomic policy of a country is formulated by its bureaucracy, collectively referred to as the helmsman (see (Koopmans 1951), (Lovell, Pastor, and Turner 1995)). Although there are countrywise differences in size and organizational structure of this bureaucracy, in the present context, it is assumed for relative assessment of their performances that each country has one helmsman for each single year. In the parlance of production economics, this essentially means that one input, viz., helmsman provides varying amounts of services and that every country-year observation has exactly one helmsman. With the input vector thus collapsing to a scalar of unit value for every country in every year, the present study seeks to compare the outputs across the countries.

Assuming that the helmsman provides services in respect of six macroeconomic variables, the macroeconomic performance function $\left(P_{i}\right)$ of a country for the period "t" may be written as:

$P_{i t}=f\left(g_{i t}, P G_{i t}, u_{i t}, b_{i t}, I_{i t}, C A_{i t}\right)$

Here $P_{i t}$ 's are evaluated as relative scores in terms of differential capacities of the helmsmen (of the individual countries) in providing (optimizing) the variables, which stand for the growth rate of real GDP, real per capita GDP, unemployment rate, budget balance, rate of inflation, and current account balance, respectively. It must be mentioned here that while the increase in the provision of some of the variables in the parentheses of (1) leads to a betterment of the economic position of a country, a similar change in the others deteriorates it. The former ( $g, P G, b$, and $C A$ ) constitutes the "benefit attributes" and the latter $(u, I)$,

\footnotetext{
${ }^{7}$ The selection of variables categorized as benefit and cost attributes considering their possible impact on the well-being of a country (for implementing the TOPSIS) has been enunciated in detail.
}

the "cost attributes". The optimization exercise for the helmsman in each country will mean maximization of the benefit attributes and minimization of the cost attributes $^{9}$. Now, writing down the output (service) vector for each country as $x(i)$, we write: $x(i)=\left\{x_{i 1}, x_{i 2}, x_{i 3}, x_{i 4}, x_{i 5}, x_{i 6}\right\}, x_{i j}$ being the value of the $i^{\text {th }}$ country with respect to the $j^{\text {th }} \quad(j=g, P G, u, b, I, C A)$ service in any particular year; the output matrix (say, $X$ ) for, say, n countries, is:

$$
X=\left[\left(x_{i j}\right)\right]_{n \times 6}=\left[\begin{array}{cccccc}
x_{11} & x_{12} & x_{13} & x_{14} & x_{15} & x_{16} \\
x_{21} & x_{22} & x_{23} & x_{24} & x_{25} & x_{26} \\
\cdot & . & . & . & . & \cdot \\
. & . & . & . & . & . \\
\cdot & . & . & . & . & . \\
\cdot & . & . & . & . & . \\
x_{n 1} & x_{n 2} & x_{n 3} & x_{n 4} & x_{n 5} & x_{n 6}
\end{array}\right]
$$

We apply the technique of MCDM onto the matrix X, and assess the performances of countries as relative scores $\left(P_{i}{ }^{\prime} \mathrm{s}\right)$. MCDM is a sub-discipline of operations research that explicitly considers multiple criteria in the decision-making process (Triantaphyllou 2000). ${ }^{10}$ For supporting the decision-making units (DMUs) constrained by choices from among multiple criteria, MCDM seeks to structure and solve it. Typically, because of the presence of multiple criteria, there exists no unique solution to an MCDM. By incorporating the preference structures of the DMUs, solutions can be differentiated and ordered accordingly. The optimal solution can be interpreted and obtained in different ways. One interpretation would consist in choosing the "best" alternative from a set of available alternatives (where "best" can be interpreted as "the most preferred alternative" to a decision maker); another, in choosing a small set of good alternatives, or grouping alternatives into different preference sets. An extreme interpretation might lie in finding all "efficient" or "non-dominated" alternatives. A non-dominated

\footnotetext{
${ }^{8}$ The level of objective economic malaise as measured by the un-weighted sum of inflation and unemployment rate is known in the literature as the "discomfort index" (or "Okun's misery Index"). Studying with a reported well-being data for thirteen European regions and USA, (Tella, Macculloch, and Oswald 2001) proved that there in fact exists a social welfare function of the form $W(I, u)$; people appear to be happier when $I, u$ are low.

${ }^{9}$ The issue of mutual interdependence/trade-offs between the attributes is an important issue here. Normally one has to compromise certain criteria for the others.

${ }^{10}$ In our daily lives, we usually weigh multiple criteria implicitly and we may be comfortable with the consequences of such decisions as are made on intuition alone. On the other hand, when stakes are high, it is important to properly structure the problem and explicitly evaluate multiple criteria. Structuring complex problems well and considering multiple criteria explicitly lead to more informed and better decisions.
} 
solution has the property that it is impossible without sacrificing at least one criterion to veer from it to any other solution. Therefore, it makes sense for the DMU to choose a solution from the non-dominated set. Otherwise, it could do better in terms of some or all of the criteria, and not do worse in any of them. Generally, however, the set of non-dominated solutions is too large to be presented to the DMU for its final choice. Hence, one needs tools to help the DMU to focus on its preferred solutions (or alternatives).

The basic premise here is the data matrix $X=\left[\left(x_{i j}\right)\right]_{n \times 6}$. Assuming that the utility derived from $g, P G, b, C A$ is monotonically increasing and that from $u, I$ is monotonically decreasing, $P_{i}$ 's can be estimated by integrating the elements of the $i^{\text {th }}$ row of $X$ with reference to some ideal and negative ideal situations (Lertprapai 2013). In absence of any natural ideal and non-ideal rows, though, optimal solution to the MCDM problem is obtained by defining two artificial points in the six-dimensional space, having respectively the best and worst values of all the attributes considered. The first point is the "positive ideal solution" (PS) and the other is the "negative ideal solution" (NS). The relative performances of each country can thus be judged by their proximities to each of these preference poles. This is the intuitive idea underlying the TOPSIS methodology (Hwang and Yoon 1981); optimal solutions are defined to be those that are simultaneously farthest from NIS, and closest to PIS. The relevant question is now the distribution of weights among the attributes in Eqn. 1 each of which indicates specific macroeconomic policy goals and thus varies across countries and over different periods. Although governments set out official goals, it remains difficult, however, to attach a precise numerical weight to each of the goals. Thus, intuitively it seems attractive to design a procedure for unequal weighting. Given X, we resort to a procedure of mathematical modelling and determine thereof, the year-specific attribute weights using the concept of "entropy" ((Golan 2006), (Maasoumi 1993) $)^{11}$. Specifically, we use the

\footnotetext{
${ }^{11}$ As we don't have recourse to the subjective assessment of the policy makers about the importance of each policy objective, we look for solution by using mathematical models regardless of decision makers' preferences. Entropy is often taken to be a measure of the disorder of a system (or differently, of its progress towards "thermodynamic equilibrium") and is determined by the number of specific ways in which the system may be arranged. The entropy of an isolated system never decreases, because isolated systems spontaneously evolve towards thermodynamic equilibrium, which is the state of maximum entropy. In the modern microscopic interpretation of statistical mechanics, entropy is the amount of additional information needed to specify the exact physical state of a system, given its thermodynamic specification. The role of thermodynamic entropy in various thermodynamic processes can thus be understood by realising how and why that information changes as the system evolves from its initial condition. Viewed in terms of information theory, the entropy state function is simply the amount of information that would be needed to specify the full microstate of the system.
}

Shannonian concept of entropy $(H(X))$; weights are distributed among the attributes taking into account the differences in the magnitudes of information disseminated from each of them (attributes), the entropy state function being simply the amount of information that would be needed to specify the full microstate of the system ${ }^{12}$.

For extracting the necessary information, first $X$ is normalized so as to scale down the attributes between zero and one. Letting $(.)_{\min },(.)_{\max }$ denote respectively the minimum and maximum values of (.), the normalization rules are:

$y_{i j}=\frac{\left(x_{i j}\right)-\left(x_{i j}\right)_{\min }}{\left(x_{i j}\right)_{\max }-\left(x_{i j}\right)_{\min }}$ (for benefit attributes) \&

$y_{i j}=\frac{\left(x_{i j}\right)_{\max }-\left(x_{i j}\right)}{\left(x_{i j}\right)_{\max }-\left(x_{i j}\right)_{\min }}$ (for cost attributes)

From the transformed data matrix $Y=\left[\left(y_{i j}\right)\right]_{n \times 6}$, the relative scores of alternatives (across criteria) are found as $a_{i j}=\frac{y_{i j}}{\sum_{i=1}^{n} y_{i j}}$,

The amount of decision information contained in $A=\left[\left(a_{i j}\right)\right]_{n \times 6}$ and emitted from each criterion can now be measured by the entropy value: $e_{j}=-\frac{1}{\ln n} \sum_{i=1}^{n} a_{i j} \ln a_{i j} ; 0 \leq e_{j} \leq 1^{13}$.

The degree of divergence $\left(d_{j}\right)$ of the average intrinsic information contained in each criterion measured as $\left(d_{j}=1-e_{j}\right)$ essentially represents the inherent contrast intensity of the $j^{\text {th }}$ criterion (Deng, Yeh, and Willis 2000). The more divergent the relative scores $a_{i j}, \forall i=1(1) n$ for the criterion $\mathrm{j}$, the higher the corresponding $d_{j}$ and the more important the specific criterion (Zeleny 1982). This essentially means that a criterion is less important (i.e., it has a smaller weight) if the variation in the relative scores $\left(a_{i j}\right)$ over the countries is less for that criterion. The weights for each criterion are given by $w_{j}\left(=\frac{d_{j}}{\sum_{k=1}^{m} d_{k}}\right)$, which are used subsequently in implementing the TOPSIS.

\footnotetext{
${ }^{12} H(X)$ is expressed in terms of a discrete set of probabilities $\left(p_{i}\right)$ as: $H(X)=-\sum_{i=1}^{n} p\left(x_{i}\right) \log p\left(x_{i}\right)$. As a measure of the uncertainty inherent in information theory, it has been formulated by using the probability theory such that this uncertainty is more pronounced in the cases with broad distributions than in the cases with narrow peaked distributions (Sleigh et al. 2001).

${ }^{13}$ The (-) sign in the above equation ensures that $e_{j} \geq 0$ (since, $a_{i j} \leq 1$ ).
} 


\section{The TOPSIS Algorithm}

i. First, the various attribute dimensions are converted into non-dimensional entities in order to allow comparisons among them. TOPSIS uses a vector-normalization process which means that raw data is transformed such that all columns (attributes) have the same unit length vector $^{14}$. An element of the normalized decision matrix $\left(r_{i j}\right)$ is found by dividing the raw criterion score $\left(x_{i j}\right)$ by the sum of the squared scores of all countries of a particular category, i.e., $r_{i j}=\frac{x_{i j}}{\sqrt{\sum_{i=1}^{n} x_{i j}^{2}}}$

ii. Next, the weighted normalized decision matrix $(V)$ is constructed by multiplying each element $\left(r_{i j}\right)$ of the normalized decision matrix with its associated weight $w_{j}$, i.e., $(V)=\left[\left(v_{i j}\right)_{n \times 6}\right]$, where $v_{i j}=r_{i j} \times w_{j} ; \sum w_{j}=1$

iii. The positive ideal solution (PS) $A^{+}$is found by maximizing the benefit criteria and minimizing the cost criteria, i.e., $A^{+}=\left\{v_{1}^{+}, v_{2}^{+}, v_{3}^{+}, \ldots, v_{m}^{+}\right\}$,

where $v_{j}^{+}=\left\{\max _{i} v_{i j}, j \in J: \min _{i} v_{i j}, j \in J^{\prime}\right\} ; J$ being the set of benefit attributes and $J^{\prime}$ the set of cost attributes.

The negative ideal solution (NS) $A^{-}$is found by minimizing the benefit criteria and maximizing the cost criteria, i.e., $A^{-}=\left\{v_{1}^{-}, v_{2}^{-}, v_{3}^{-}, \ldots, v_{m}^{-}\right\}$,

where $v_{j}^{-}=\left\{\max _{i} v_{i j}, j \in J^{\prime}: \min _{i} v_{i j}, j \in J\right\} ; J$ being the set of benefit attributes and $J^{\prime}$ the set of cost attributes.

iv. The distance of each DMU from PS, $S_{i}^{+}$can be found in the multidimensional attribute space by

\footnotetext{
${ }^{14}$ By establishment of uniform vector lengths between attributes resulting in a non-linear transformation, the maximum and minimum values may not be similar between separate normalized criteria. This renders the transformation hard to visualize unlike the linear scale normalization used in linear comparison models such as Simple Additive Weighting Method. The linear scale normalization is based on dividing the actual criterion score by the maximum possible value in that category and as such may be invariant to the addition (deletion) of new alternatives to the existing dataset. Use of vectornormalization in TOPSIS ensures that normalized scores will vary not only according to the values of the scores being normalized, but also according to the number of alternatives on the list.
}

using the Mahalanobis distance function (Mahalanobis 1936) as ${ }^{15}$ :

$$
S_{i}^{+}=\left(v_{i}-A^{+}\right) \Delta^{T} \Sigma^{-1} \Delta\left(v_{i}-A^{+}\right)^{T} ;\left\{v_{i}=\left(v_{i j}\right)_{j=1(1) m}\right\},
$$

where $\Delta$ a diagonal matrix is formed of entropy weights $\left(w_{j}\right)$ and $\Sigma$ is the variance-covariance matrix of the normalized data matrix in $(i)$.

The distance of each DMU from the NS, $S_{i}^{-}$can similarly be found as:

$$
S_{i}^{-}=\left(v_{i}-A^{-}\right) \Delta^{T} \Sigma^{-1} \Delta\left(v_{i}-A^{-}\right)^{T}
$$

v. The "relative closeness" to the ideal solution (PS) is calculated as:

$$
\begin{aligned}
& C_{i}^{+}=\frac{S_{i}^{-}}{S_{i}^{+}+S_{i}^{-}} ; 0 \leq C_{i}^{+} \leq 1, i=1(1) n \\
& \Rightarrow C_{i}^{+}=1 \text { if } v_{i}=A^{+} \& C_{i}^{+}=0 \text { if } v_{i}=A^{-}
\end{aligned}
$$

The above relations demonstrate that the relative closeness' coefficient, which is the aggregating function, models the closeness of an alternative to the ideal solution compared to its closeness to the negative ideal solution. In other words, if an alternative is closer to $A^{+}$than to $A^{-}$then $C_{i}^{+}$approaches unity, but if an alternative is closer to $A^{-}$than to $A^{+}$, then $C_{i}^{+}$ approaches zero. Evidently, therefore, the notion of 'relative closeness' corresponds to the principle of compromise that the best alternative should simultaneously have the shortest distance from the PS and the farthest distance from the NS. We treat $C_{i}^{+}$as estimate of $P_{i}$. Higher the value of $C_{i}^{+}$the better the performance of the particular country in a particular year, and accordingly, the former will be ranked higher than the one having a smaller score. ${ }^{16}$

\footnotetext{
${ }^{15}$ Mahalanobis distance is used to calculate the distance between two centroids (Legendre and Legendre 1998) allowing for oblique positioning of an "elliptic envelope" within a multidimensional attribute space (Farber and Kadmon 2003). The idea is that the distance between similar objects should be relatively smaller than that between dissimilar ones.

Mathematically, the Mahalanobis distance between a vector $\mathrm{x}$ and a set $\mathrm{S}$ of vectors (matrix) is defined as:

$D^{2}=(x-m)^{T} C^{-1}(x-m)$ where $\mathrm{m}$ is the mean vector and $\mathrm{C}$ stands for the covariance matrix of S (Clark, Dunn, and Smith 1993). The rows of S stand for observations and the columns for the status of attributes. The vector $m$ represents the optimum conditions and $x$, the status of attributes for any particular observation (country). When the Variance-Covariance matrix is the Identity matrix, the Mahalanobis distance reduces to the usual Euclidean distance.

${ }^{16}$ The methodology of TOPSIS suffers from the drawback that in defining the relative closeness coefficient as in (v) which is rather arbitrarily chosen, the relative importance of two outcomes (i.e., PS \& NS) is not considered (Opricovic and Tzend 2004). This issue can be tackled by incorporating the concept of "grey correlation analysis" (Deng 1989) in TOPSIS. Also we ignore here the potential problem of "rank reversal" which can be addressed using a modified version of TOPSIS (Socorro García-Cascales and Teresa Lamata 2012).
} 
Stacking the $P_{i}$ 's over the years, we get a definite idea about the position of any particular country in terms of its performance in a given year as well as about how its position (ranking) has changed relative to others over the years ${ }^{17}$.

\subsection{Comparing Country Rankings Over the Years}

We follow (Bar-llan, Levene, and Lin 2007) and use the following measures to statistically assess the pattern of changes in the Top-k rankings over the years.

The Overlap (O) measure counts the number of countries that appear in both the Top-k lists.

The Footrule $(F)$ is applied to a set of overlapping elements (i). If the result of the re-rankings (after eliminating the non-overlapping elements from both the lists) is two permutations $\sigma_{1}$ and $\sigma_{2}$ on $1,2 \ldots \mathrm{S}$, where $S$ is the number of overlapping elements (countries); the normalized Spearman's Footrule (Fr) (Diaconis and Graham 1977) on these transformations is computed as $\quad N F r=\frac{F r^{|S|}}{\max \left(F r^{|S|}\right)} ; \quad$ where $\operatorname{Fr}^{|S|}\left(\sigma_{1}, \sigma_{2}\right)=\sum_{i=1}^{|S|}\left|\sigma_{1}^{i}-\sigma_{2}^{i}\right| ;$ $\max \left(F r^{|S|}\right)=\frac{1}{2}|S|^{2}$, when $\quad|S| \quad$ is even and $\frac{1}{2}(|S|+1)(|S|-1)$, when $|S|$ is odd.

Higher the value of $\mathrm{NFr}$ the higher the disarray between the rankings - a value of 1 indicates complete disarray (i.e., the lists appearing in opposite orders); a value of zero implies similarity (i.e., zero positional shift) in the relative rankings (of the Top-k positions) for the specific year.

For comparing two non-identical rankings, Spearman's Footrule is extended following (Fagin, Kumar, and Sivakumar 2003), which assigns a rank (= k) to the non-overlapping elements as well. Fagin's G measure is computed as:

$$
\begin{aligned}
& G^{(k+1)}=1-\frac{F^{(k+1)}}{\max \left(F^{(k+1)}\right)} ; F^{(k+1)}\left(\tau_{1}, \tau_{2}\right)=2(k-z)(k+1)+ \\
& \sum_{i \in z}\left|\tau_{1}(i)-\tau_{2}(i)\right|-\sum_{i \in S} \tau_{1}(i)-\sum_{i \in T} \tau_{2}(i) .
\end{aligned}
$$

\footnotetext{
${ }^{17}$ It is however not possible to tell whether the change is due to the changes in its own macroeconomic policies or environment, or due to the changes in the relative performance of others (countries). In other words, any temporal comparison among the scores $\left(P_{i}{ }^{\prime} s\right)$ is not possible as the reference points (PS/NS) are year-specific.
}

Here $Z$ is the set of overlapping elements, $z$ is the size of $Z, S$ is the set of elements that are only in the first list and $T$ is the set of elements that appear in the second list only ${ }^{18}$.

The $M$ measure introduced by (Bar-llan, Levene, and Lin 2007) improves upon the Fagin's measure which gives more weight to the non-overlapping elements and is computed as:

$M^{(k)}=1-\frac{N^{(k)}}{\max \left(N^{(k)}\right)} ;$ where

$\max \left(N^{(k)}\right)=2 \sum_{i=1}^{k+1}\left(\frac{1}{i}-\frac{1}{k+1}\right)$ and

$N^{(k)}\left(\sigma_{1}, \sigma_{2}\right)=\Sigma_{Z}\left|\frac{1}{\sigma_{1}(i)}-\frac{1}{\sigma_{2}(i)}\right|+\sum_{S}\left|\frac{1}{\sigma_{1}(i)}-\frac{1}{k+1}\right|+$

$\Sigma_{T}\left|\frac{1}{\sigma_{2}(i)}-\frac{1}{k+1}\right|$

Here $\mathbf{Z}$ is the set of overlapping elements, $\sigma_{1}(i)$ being the rank of element $i$ in the first set, $\sigma_{2}(i)$ being the rank of element $i$ in the second set. $S$ is the set of elements appearing only in the first list and $\mathrm{T}$ is the set of elements appearing only in the second list.

The $M$ measure being a normalized similarity measure, we use (1-M) as the measure to quantify the positional shifts in the Top-k relative rankings of countries.

For an overall assessment in the rankings (over the years) and for exploring any systematic pattern in the latter, i.e., whether higher rankings are (always) associated with some specific countries, the lower or medium ones being fixed with some others and if so, the degree of this association (or there is no such relationships at all), we classify the ranks on an ad-hoc benchmark, viz., that the top ten rankings in each year are classified as "A", the next 10 rankings as "B", the subsequent 10 as " $C$ " to be followed by " $D$ " for the rest. The categories (A, B, C \& D) vis-a-vis the lists of countries form a two-way contingency table onto which the technique of Correspondence Analysis (CA) (Greenacre 2002) is applied to test the null hypothesis that the rows (countries) and columns (status) are statistically independent. If the frequency of occurrence of status "j" for any country "i" be $k(i, j)$, and $k(i)$ be the corresponding row total, then $k(i)=\sum_{j=1}^{J} k(i, j) \forall i$. The relative frequency of category "j" for country "i" is,

\footnotetext{
${ }^{18}$ See (Bar-Ilan, Mat-Hassan, and Levene 2006)
} 
thus: $f_{j}^{i}=\frac{k(i, j)}{k(i)}$ and the profile of the $i^{\text {th }}$ country is: $f_{J}=\left\{f_{j}^{i} \mid j \in J\right\}$. The notion of a profile for a country allows one to express the categorical structure independent of its size. Comparison of the unit profile, $f_{j}^{i}$ with the mean profile $f_{J}$ thus reveals the structural departure of the $i^{\text {th }}$ country from the general global structure, in respect of the observed indicators. Now, if $N(I)$ be the set of I unit profiles in dimension-J space, i.e., $N(I)=\left\{f_{J}^{i} \mid i \in I\right\}$, the centre of gravity (centroid) of the cluster $N(I)$ is $g_{J}=\sum_{i=1}^{I} f_{i} f_{J}^{i}$ where $f_{i}$ is the relative weight/marginal frequency of the $i^{\text {th }}$ country; $f_{i}=\frac{k(i)}{k}, k=\sum_{i=1}^{I} \sum_{j=1}^{J} k(i, j)$. The intuitive comparison between the unit profiles is next quantified by the $\chi^{2}$ distance: $d^{2}\left(f_{J}^{i}, f_{J}^{i^{\prime}}\right)=\sum_{j=1}^{J}\left(\frac{1}{f_{j}}\right)\left(f_{j}^{i}-f_{j}^{i^{\prime}}\right)^{2}$

The whole variability observed in the cluster of population units $N(I)$ may now be summarized based on the concept of inertia, built with the chi-squared distance of each profile from the centre of gravity: $I_{G}[N(I)]=\sum_{i=1}^{I} f_{i} d^{2}\left(g_{J}, f_{J}^{i}\right)$. This in effect measures the degree of difference between the different groups and can be represented optimally in the eventual map by using weighted least squares, the row profile points being projected onto the best-fitting plane. The coordinates of these points are called principal coordinates, being referred to the principal axes of the space and each principal axis accounting for a certain amount of the total inertia (the principal inertia). A statistically significant $\chi^{2}$ value will signify the rejection of the null indicating that the categories and countries are dependent; this will imply existence of a systematic pattern in the distribution of rankings across the countries.

\section{DATA AND RESULTS}

The paper proposes a macroeconomic performance indicator $\left(P_{i}\right)$ and assesses relative performances of countries with respect to six macroeconomic variables, viz., the growth rate of real GDP, real per capita GDP, unemployment rate, fiscal balance, rate of inflation, and current account balance. The data constitutes a wide spectrum comprising as many as 48 countries spanning the global economy - including the developed economies like the USA, Japan and the UK, the countries belonging to the European Union, as well as some emerging Asian and Latin American economies. The annual data set used in constructing the decision matrix $X$ is compiled from World Bank Economic Indicator Database for the period 2000$2012 .^{19}$ A brief description of the variables so as to categorize them as benefit/cost types depending on their possible impact on the well-being ${ }^{20}$ of an economy is provided below:

The gross domestic product (GDP) is one of the primary indicators of a country's economic performance. GDP is the sum of gross value added by all resident producers in the economy plus any product taxes minus any subsidies not included in the value of the products. ${ }^{21}$ The variable GDP has been considered in both its level and difference forms for a more meaningful comparison between the developed and the emerging economies. This is because the growth rate of real GDP is usually higher in an emerging economy, which if considered in isolation, may distort the true macroeconomic picture. The per capita GDP (PGDP), i.e., GDP divided by the population size, ${ }^{22}$ is a measure of the average wealth of the population of a nation. The concept is often utilised to estimate a country's standard of living, and hence, is useful in comparing country-wise GDPs. A rise in PGDP signals growth in the economy and tends to transform it as an increase in productivity. The growth rates in PGDP are found by taking the real values of PGDP compared to a base year.

A balanced budget (of a government) is one where revenues equal expenditures and neither a deficit nor a surplus exists. Broadly, it refers to a budget certainly with no deficit, but possibly with a surplus. An important macroeconomic concept in this regard is fiscal rectitude, which consists in keeping the national debt under control. $^{23}$ In general, economists are worried

\footnotetext{
${ }^{19} \mathrm{http}: / /$ data.worldbank.org/indicator

${ }^{20}$ It is to be mentioned here that although the apparent reputation earned by a country is based on a number of heterogeneous dimensions, the present study investigates only a limited number of these, i.e., the most frequently encountered macroeconomic indicators. The reality is that the general public making an assessment of a country's macroeconomic performance usually is concerned about some additional characteristics, that are qualitative in nature, viz., the work ethics of population, the quality of public administration, the degree of political corruption, the attitude towards laws and regulations etc. The subjective perception of these features shape the image of a country's macroeconomic performance (Moesen and Cherchye 1998).

${ }^{21}$ It is calculated without making deductions for depreciation of fabricated assets or for depletion and degradation of natural resources. Dollar figures for GDP are converted from domestic currencies using single year official exchange rates (World Bank definition).

${ }^{22}$ GDP per capita is estimated by the World Bank as gross domestic product divided by midyear population.

${ }^{23}$ When vibrant macroeconomic conditions prevail, tax revenues are usually buoyant; consequently, the government seldom needs to have recourse to borrowing for stimulating the economy. However, during times of economic downturn, tax revenues decline, and governments have recourse to borrowing to bring the economy back to growth. The implication of an increasing interest burden is that government revenues will be diverted to pay for financing costs, instead of being used for purposes that are more productive.
} 
when government debt, which is the most common means of financing a government deficit, rises sharply as a proportion of GDP. Hence, having a balanced budget or surplus has been treated as a non-significant entity while comparing the macroeconomic positions of countries in this paper. Other variables remaining the same, a country with a budget surplus has been treated on a par with another country without it, whereas a country with a budget deficit has been given a lower ranking than another with a lesser deficit or without it altogether. ${ }^{24}$

Balance of payment, a concept signifying a country's external economic performance ranks high as an indicator of a country's macroeconomic performance. To be specific, an appreciation of surplus on the current account balance (CAB) points to an enhancement in the country's macroeconomic performance, whereas a deficit is regarded as a bad signal for the economy, where $C A B$ is the sum of three components: net exports of goods and services, net primary income, and net secondary income. The "Calmfors-Driffil" index of performance (Calmfors and Driffill 1988) prescribes the addition of the unemployment rate to the deficit on the current account as a percentage of GDP, thus ensuring a better macroeconomic performance to be associated with a lower index value. In fact, it is designed to penalise countries that pursue a low level of unemployment through an expansionary policy leading to a deficit on the current account.

The variables, inflation and unemployment, have been taken to be the cost variables insofar as enhancement in respect of these variables creates economic and social cost for a country, thereby lowering its economic position. The degradation in the macroeconomic position of a country has been envisaged in the literature by what is called the "misery index" ${ }^{\prime 25}$. In economic terms, this means that a rise in inflation coupled with high unemployment leads to lower consumer expenditures and contributes to an economic slow-down. Many distinguished economists have argued that prices should continuously fall at the real rate of interest. No central bank, however,

\footnotetext{
${ }^{24}$ The new "misery index" adds together a country's budget deficit, as a percentage of GDP and its unemployment rate. The original misery index, created by the economist Arthur M. Okun, added together a country's unemployment rate and its inflation rate. That index came to symbolize stagflation, a significant problem of the 1970s, when consumer prices continued to rise even as economies stagnated and unemployment rose.

${ }^{25}$ The index was developed by Arthur Okun to characterize the economic condition of a country (see (Okun 1970), (Okun 1978), (Okun 1981)). Also see Footnote 8.
}

operates on that principle. The fact is that the negative inflation at that rate would be ideal, normally, in a perfect world. But imperfections of many kinds tend to tilt the optimum monetary policy towards less deflation, or even mild inflation (Sinclair 2003). Although a fall in inflation results in a fall in the misery index, a negative inflation or deflation has in fact a debilitating effect on the economy (Denhart and Shales 2012). It is to be mentioned here that the crucial assumption underlying the TOPSIS methodology is that the criteria must be monotonic in nature. Assuming that both positive and negative inflations are detrimental to the economy, a negative inflation has been treated in this paper as equivalent to a positive inflation of equal magnitude and hence the inflation data has been taken in its modulus form to address the problem of nonmonotonicity (in utility of the criterion). Countries having larger deviations of inflation rates from the optimal rate are supposed to have a lower value of performance scores than the ones having smaller deviations. ${ }^{26}$

After estimating the year-specific entropy weights of the attributes, for comparison of performances across the years we have chosen to take the mean of the year-wise estimates of weights $\left(w_{j}^{(t)}{ }^{\prime} s\right)$ as the attribute weight $\left(w_{j}\right)$ i.e., $w_{j}=\frac{\sum_{t=2000}^{2012} w_{j}^{(t)}}{13}$. Table 1 gives the year-wise rankings of countries based on the TOPSIS scores ${ }^{27}$. It may be noted here that the rankings do not simply reflect the "rank aggregations" across the individual goals pursued by policymakers ${ }^{28}$. The performance scores rather do correspond to their relative closeness to the ideal solution (PS) based on a Mahalanobis distance metric (Mahalanobis 1936). Here application of a Mahalanobis distance function as against the normal Euclidean distance metric is essentially meant to take care of the inherent correlation structure in the data matrix. This means that the results will converge in case the variancecovariance structure of the underlying data matrix collapses to an identity matrix. Further, if the maximum possible weight of one is attached to a single criterion, say GDP growth (implying zero weights for others); it leads us to the original rankings of countries according

\footnotetext{
${ }^{26}$ Among monetary authorities in industrial countries that self-classify as inflation targetters, for example, inflation targets are concentrated at a level of two percent per year (Schmitt-Grohe and Uribe 2010). There will however not be much variations in the relative rankings if the optimal level (of inflation) is determined by minimization of the corresponding cost attribute.

${ }^{27}$ The scores are not reported here due to lack of space.

${ }^{28}$ The rank aggregation problem is to combine many different rank orderings on the same set of candidates, or alternatives, in order to obtain a "better" ordering. Rank aggregation has been studied extensively in the context of social choice theory, where several "voting paradoxes" have been discovered (Dwork et al. 2001).
} 
Table 1: Year-Wise Country Rankings Based on TOPSIS Scores

\begin{tabular}{|c|c|c|c|c|c|c|c|c|c|c|c|c|c|}
\hline Country & 2000 & 2001 & 2002 & 2003 & 2004 & 2005 & 2006 & 2007 & 2008 & 2009 & 2010 & 2011 & 2012 \\
\hline Argentina & 38 & 40 & 38 & 19 & 25 & 22 & 23 & 22 & 13 & 16 & 18 & 17 & 26 \\
\hline Australia & 25 & 25 & 26 & 34 & 31 & 31 & 30 & 29 & 25 & 26 & 29 & 28 & 25 \\
\hline Austria & 19 & 18 & 11 & 13 & 17 & 16 & 14 & 13 & 10 & 13 & 16 & 16 & 16 \\
\hline Belgium & 9 & 9 & 9 & 12 & 14 & 18 & 17 & 15 & 22 & 21 & 21 & 26 & 28 \\
\hline Brazil & 36 & 38 & 37 & 36 & 26 & 28 & 29 & 32 & 21 & 28 & 24 & 30 & 35 \\
\hline Chile & 26 & 30 & 28 & 27 & 19 & 19 & 18 & 19 & 26 & 18 & 17 & 20 & 22 \\
\hline China & 22 & 24 & 21 & 22 & 20 & 15 & 12 & 10 & 4 & 7 & 10 & 12 & 9 \\
\hline Cyprus & 31 & 29 & 32 & 31 & 35 & 34 & 33 & 38 & 41 & 44 & 45 & 45 & 47 \\
\hline Czech Republic & 34 & 37 & 40 & 40 & 36 & 29 & 31 & 31 & 23 & 34 & 39 & 36 & 44 \\
\hline Denmark & 13 & 8 & 12 & 10 & 11 & 9 & 13 & 14 & 15 & 14 & 11 & 10 & 14 \\
\hline Germany & 21 & 20 & 17 & 17 & 12 & 12 & 9 & 9 & 7 & 9 & 9 & 9 & 6 \\
\hline Greece & 41 & 43 & 42 & 42 & 39 & 40 & 45 & 46 & 46 & 47 & 48 & 48 & 48 \\
\hline Hong Kong SAR & 7 & 7 & 6 & 4 & 4 & 4 & 4 & 3 & 2 & 5 & 7 & 8 & 13 \\
\hline Hungary & 46 & 42 & 46 & 46 & 46 & 45 & 43 & 42 & 37 & 35 & 25 & 19 & 29 \\
\hline Iceland & 35 & 28 & 16 & 33 & 37 & 44 & 47 & 40 & 48 & 48 & 46 & 43 & 38 \\
\hline India & 32 & 34 & 33 & 35 & 34 & 38 & 37 & 35 & 32 & 36 & 28 & 34 & 37 \\
\hline Indonesia & 15 & 19 & 23 & 21 & 24 & 30 & 28 & 26 & 19 & 15 & 22 & 18 & 19 \\
\hline Ireland & 14 & 16 & 19 & 18 & 18 & 21 & 21 & 24 & 38 & 39 & 40 & 27 & 15 \\
\hline Italy & 20 & 21 & 25 & 23 & 22 & 24 & 26 & 21 & 31 & 31 & 37 & 38 & 41 \\
\hline Japan & 18 & 17 & 18 & 14 & 16 & 14 & 15 & 12 & 20 & 17 & 14 & 21 & 21 \\
\hline New Zealand & 27 & 27 & 27 & 28 & 32 & 36 & 34 & 33 & 36 & 23 & 34 & 40 & 34 \\
\hline Philippines & 37 & 35 & 31 & 30 & 27 & 26 & 20 & 20 & 17 & 12 & 13 & 15 & 11 \\
\hline Poland & 44 & 44 & 41 & 37 & 43 & 33 & 35 & 37 & 33 & 38 & 42 & 41 & 36 \\
\hline Portugal & 43 & 46 & 45 & 38 & 41 & 46 & 41 & 41 & 44 & 46 & 47 & 47 & 45 \\
\hline Romania & 47 & 45 & 43 & 47 & 47 & 42 & 42 & 45 & 39 & 43 & 43 & 44 & 42 \\
\hline Russia & 4 & 5 & 10 & 11 & 9 & 8 & 10 & 16 & 6 & 24 & 15 & 11 & 12 \\
\hline Singapore & 2 & 2 & 2 & 1 & 1 & 1 & 1 & 1 & 1 & 1 & 1 & 1 & 1 \\
\hline Slovak Republic & 45 & 47 & 47 & 43 & 44 & 43 & 39 & 34 & 30 & 40 & 41 & 35 & 17 \\
\hline Slovenia & 28 & 22 & 22 & 25 & 29 & 25 & 25 & 28 & 28 & 29 & 27 & 25 & 27 \\
\hline Spain & 29 & 31 & 30 & 32 & 33 & 35 & 36 & 36 & 40 & 42 & 44 & 46 & 46 \\
\hline Sweden & 8 & 6 & 8 & 7 & 7 & 7 & 7 & 6 & 5 & 8 & 6 & 7 & 5 \\
\hline Switzerland & 3 & 3 & 3 & 2 & 3 & 3 & 2 & 4 & 12 & 3 & 2 & 3 & 2 \\
\hline $\begin{array}{c}\text { Taiwan Province of } \\
\text { China }\end{array}$ & 17 & 13 & 5 & 5 & 10 & 10 & 8 & 8 & 9 & 4 & 3 & 5 & 3 \\
\hline Turkey & 48 & 48 & 48 & 48 & 38 & 37 & 38 & 39 & 35 & 41 & 38 & 42 & 39 \\
\hline United Kingdom & 24 & 23 & 24 & 24 & 23 & 23 & 27 & 25 & 29 & 30 & 35 & 32 & 43 \\
\hline United States & 23 & 26 & 29 & 29 & 30 & 32 & 32 & 30 & 34 & 32 & 33 & 39 & 33 \\
\hline
\end{tabular}




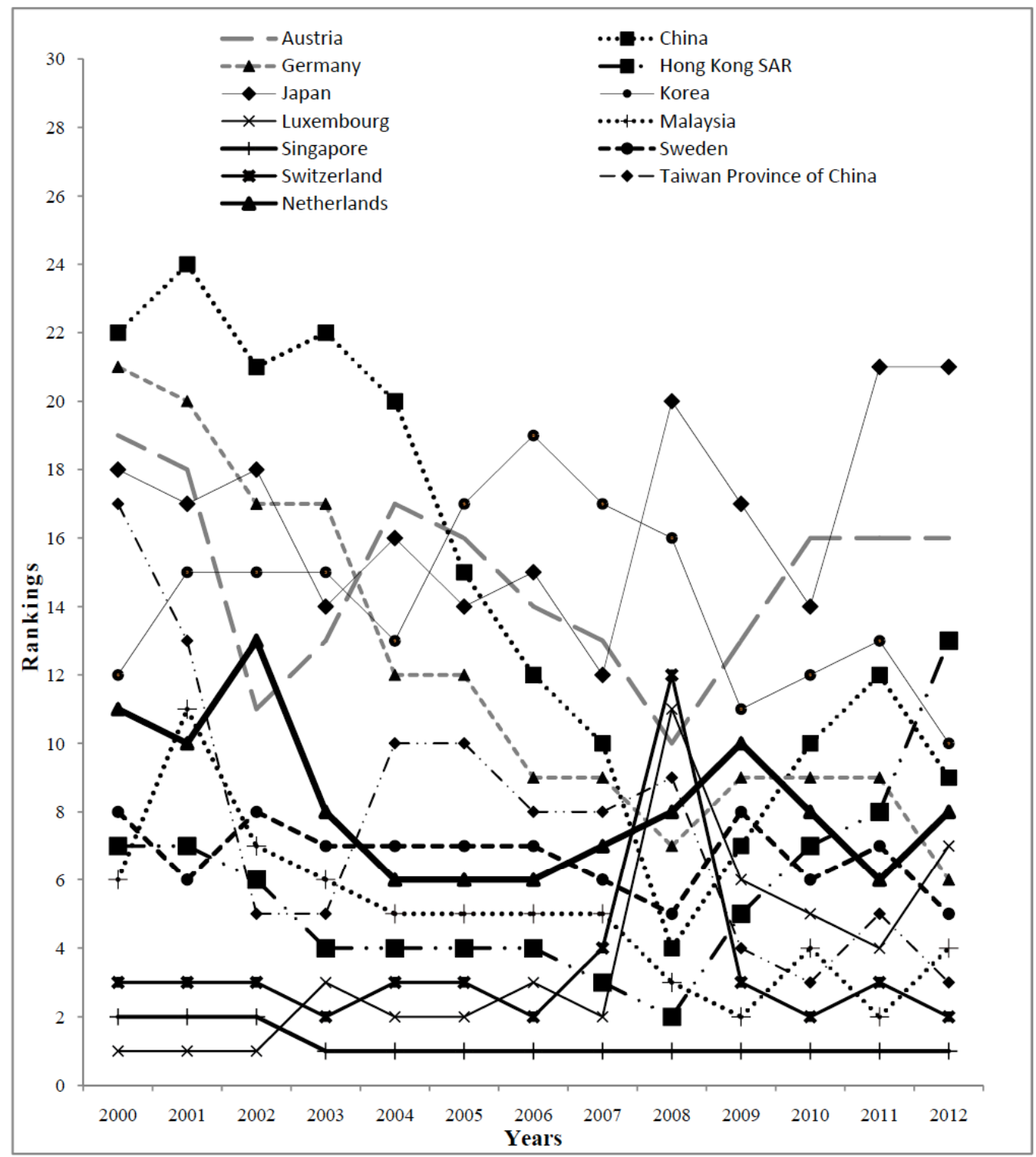

Figure 1: Rankings of Some Top Performers over the Years.

to GDP growth ${ }^{29}$. Interestingly enough, the CalmforsDriffil index and Okun index can be obtained as two special cases of the present analysis when the corresponding criteria weights for two attributes are equal and add up to 1 .

The year-wise rankings of countries based on $P_{i}$ 's immediately point to the fact that most economies do not perform equally well over the macroeconomic measures considered by policymakers and analysts. Nor are country performances very stable over time according to the composite score, unlike that indicated by a single indicator. The USA, for example, ranks

\footnotetext{
${ }^{29}$ The Table showing the ranking of countries based on composite scores alongside the ranking based on specific criterion $\left(w_{j}=1\right)$ is not shown due to lack of space.
}

among the top performers in terms of per capita GDP, but had an overall rank of 23 in the year 2000 and has performed consistently worse since. India, on the other hand, ranked second in terms of GDP growth in 2010, but had a composite rank of 28 in the same year.

According to the scores, Singapore shows up as a consistent performer all through our study period figuring at number one since 2003, prior to which it was ranked number two. ${ }^{30}$ Other countries which figure among the top 10 performers (see Figure $\mathbf{1}$ above) and

\footnotetext{
${ }^{30}$ This, for example, is in line with the ranking of the country according to several economic indices; Singapore is ranked among the top 5 nations in terms of per capita GDP, is ranked first worldwide for the ease of doing business by the World Bank for 2012, consecutively for 7 years, and has high rankings in the Index of Economic Freedom by the Heritage Foundation and The Wall Street Journal.
} 
Table 2: Measures of Disarray between Year-Wise Rankings

\begin{tabular}{|c|c|c|c|c|}
\hline Consecutive Years & $0^{*}$ & NFr & $\mathbf{G}$ & M \\
\hline $2000-2001$ & 8 & 0.13 & 0.04 & 0.03 \\
\hline 2001-2002 & 8 & 0.25 & 0.07 & 0.03 \\
\hline $2002-2003$ & 8 & 0.41 & 0.12 & 0.39 \\
\hline 2003-2004 & 9 & 0.28 & 0.10 & 0.13 \\
\hline $2004-2005$ & 9 & 0.03 & 0.01 & 0.00 \\
\hline $2005-2006$ & 9 & 0.15 & 0.05 & 0.09 \\
\hline $2006-2007$ & 9 & 0.15 & 0.05 & 0.13 \\
\hline $2007-2008$ & 8 & 0.44 & 0.13 & 0.12 \\
\hline $2008-2009$ & 8 & 0.59 & 0.17 & 0.19 \\
\hline $2009-2010$ & 10 & 0.28 & 0.13 & 0.17 \\
\hline $2010-2011$ & 9 & 0.25 & 0.09 & 0.17 \\
\hline $2011-2012$ & 8 & 0.47 & 0.14 & 0.19 \\
\hline
\end{tabular}

${ }^{*}$ Note that $\mathrm{O}$ in fact is a similarity index (in contrast to the other three indices).

have retained their positions even in the crisis- and post crisis period include Sweden, Switzerland (after slipping to rank 12 in 2008), Netherlands, Luxembourg, along with the Asian emerging markets of Hong Kong (till 2011), Taiwan and Malaysia. Germany had made it to the top 10 in 2006, having since registered significant improvement in the GDP growth and CAB scores. The Asian giant China has moved up to be among the top 10 performers since 2007, according to the composite scores as it improved by several notches in the external and government balances rankings.

Judging from an overall perspective, the Top-10 positions are relatively stable (over time) in the sense that degree of overlap between two consecutive yearwise positions is reasonably high; the Overlap (O) measure giving a maximum value of 10 and minimum of 8 . It should however be noted that despite this high degree of overlap, there are ample inter-year fluctuations among these performances. Table 2 above summarizes the magnitude of dissimilarity among the Top-10 year-wise rankings. It is observed that normalized Spearman Footrule distance (NFr) as well as the Fagin's $G$ measure reaches their highest levels for the years 2008-09, indicating widest temporal shift in the relative positions of the countries during the corresponding time interval. The $M$ index also gives support to this attaining the second highest value for the said time interval. It is interesting to note that 200405 gives the lowest values of all the three indices implying the minimum positional shifts in the top global rankings. The degree of overlap is 10 for the years 2009-10 implying that the number of countries appearing in the Top-10 is the same in the two consecutive years, high values of NFr, G and M though indicate much dissimilarity in relative positions of the countries.

The performance rankings also draw attention to the effect the recent global crisis has had on the relative position of countries in terms of their overall macroeconomic performances (see Figure 2 below). The USA, for example slid from rank 23 in 2000 to 39 in 2011, before moving up to 33 in 2012. Particularly, performances in terms of the government balances (from 3 in 2000 to 46 in 2012) and employment (from 11 in 2000 to 31 in 2012) have led to the lowering of USA's composite ranking. The UK also plunged from a rank of 24 in 2000, to 43 in 2012, due mainly to a sharp drop in terms of government balances (from 1 to 44), together with $\mathrm{CAB}$ (from 27 to 38 ) and employment (from 19 to 30). Similar is the fate of several other EU countries, particularly France, Italy, and Spain in the crisis- and post crisis years. The fiscal austerity imposed in the EU countries has had a marginal positive effect on the budget balance rankings of some of these countries but there has been sharp deterioration in the overall rankings in the years in which severe austerity policies were being followed by national governments; ${ }^{31}$ France, for example, crashed

\footnotetext{
${ }^{31}$ This result is in line with studies like (Moesen and Cherchye 1998), which investigate the performance of 20 OECD countries, half of which belongs to the $\mathrm{EU}$, in the quinquennial period before and after the Maastricht Treaty and conclude that the Maastricht criteria, particularly those with respect to excessive deficits, were too restrictive, thereby generating unfortunate macroeconomic welfare losses.
} 


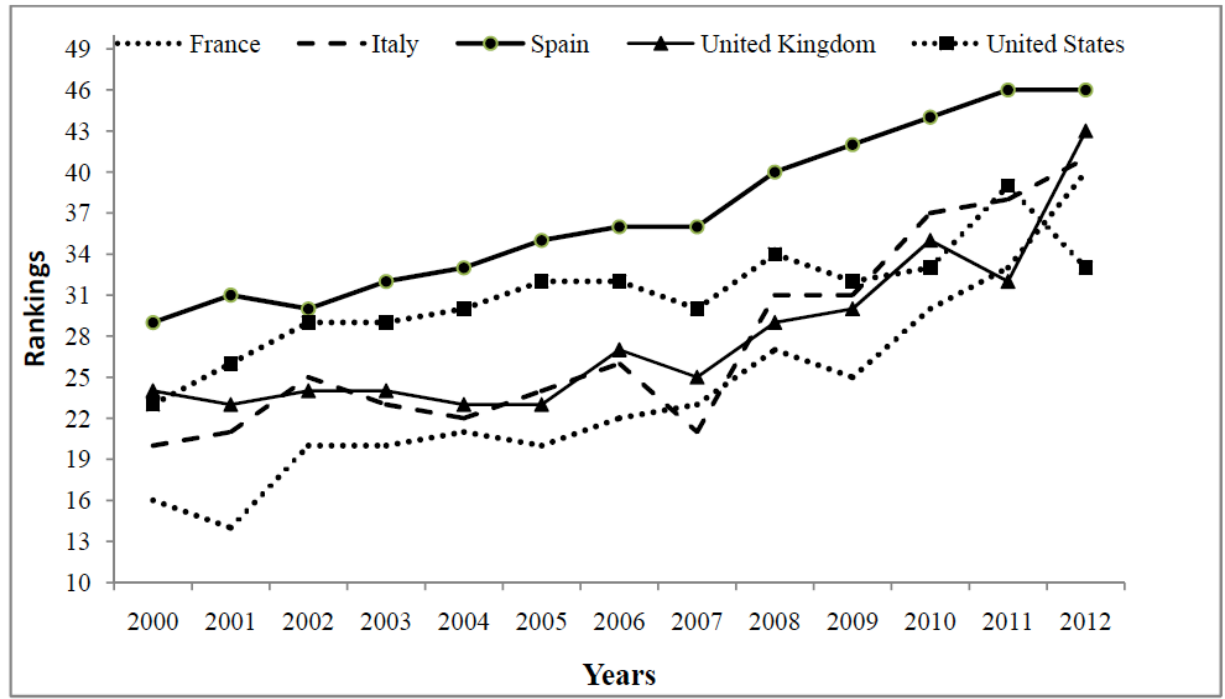

Figure 2: Rankings of Some Developed Economies over the Years.

from rank 14 in 2001 to 40 in 2012, according to the composite scores. Italy has fallen from rank 21 in 2000 to 31 in 2008, and the ranking has further deteriorated to 41 by 2012 . Spain, on the other hand, has nosedived from rank 29 in 2000 to 46 by 2012, with the budget balance ranking falling from 3 in 2007 to the last by 2012 , because of the crisis and related problems within the country.

Among the emerging Latin American countries, Mexico has moved up from rank 30 in 2000 to 20 in 2012, with its ranking according to GDP growth improving significantly from 39 in 2007 and 2010 to 8 in 2012. Chile also moved up from rank 30 in 2001 to 20 in 2011, with the budget balance rank at 2 in 2011. Brazil's composite ranking shows improvement from 38 in 2001 to 21 in 2008, with significant improvement in the $\mathrm{CAB}$ and unemployment raking; the composite rank stands at 35 in 2012.

Japan's ranking has varied between 12 in 2007 and 21 in the last two years (2011 and 2012) with a sharp deterioration in GDP growth in 2011 and a worsening of current account and government balances having an adverse effect on its ranking in 2012. Korea's performance has remained consistent with the rank varying between 10 and 19 . China ranked around 20 till 2004 and moved up to the Top 10 rankings by 2007, with jumps in the external and government balances rankings. However, though China's GDP ranking remains mostly at 1 , the country has a very low ranking in terms of per capita GDP, as corroborated by rankings by the World Bank, for example. Apart from China, Philippines is the other Asian emerging market, the scores of which have improved during the post crisis years relative to the others considered; the country has ascended from rank 37 in 2000 to 11 by 2012. India, ranked 38 in 2005 according to the composite scores; the ranking improved to 28 by 2010 , but has since slipped back to 37 by 2012 (Figure 3). India's GDP rank fell from 2 in 2010 to 7 in 2012; while the $C A B$ rank which was at 20 in 2001, descended to 36 by 2010 and finally crashed to the last position in 2012. In 2012, India is among the bottom five in terms of the performance scores for $C A B$, inflation, and budget balance, while the country steadily maintains the worst ranking in terms of per capita GDP, relative to all the countries considered in this study, even though it consistently ranks among the top 10 in terms of real GDP growth in all the years considered ${ }^{32}$.

It has been observed that synthetic macroeconomic performance scores reveal interesting information and they confront measurement with perception (Moesen and Cherchye 1998). Our results indeed show that some common perceptions about the performance of both the developed and the developing economies may be in contrast to reality if several dimensions of economic performance are considered together, rather than looking at the indicators in isolation, such as, GDP growth or per capita GDP. ${ }^{33}$ The study shows that relative rankings for a country may change quite drastically over the years, because of deterioration in some macroeconomic indicators, even though a country may persistently register a high rate of growth.

\footnotetext{
${ }^{32}$ Rankings based on individual variables are not shown in this paper. These may be supplied to interested readers.

${ }^{33}$ Such results may also lend support to studies which consider the shift of economic power from developed markets to emerging markets. The results are similar to findings by (Basu et al. 2011).
} 


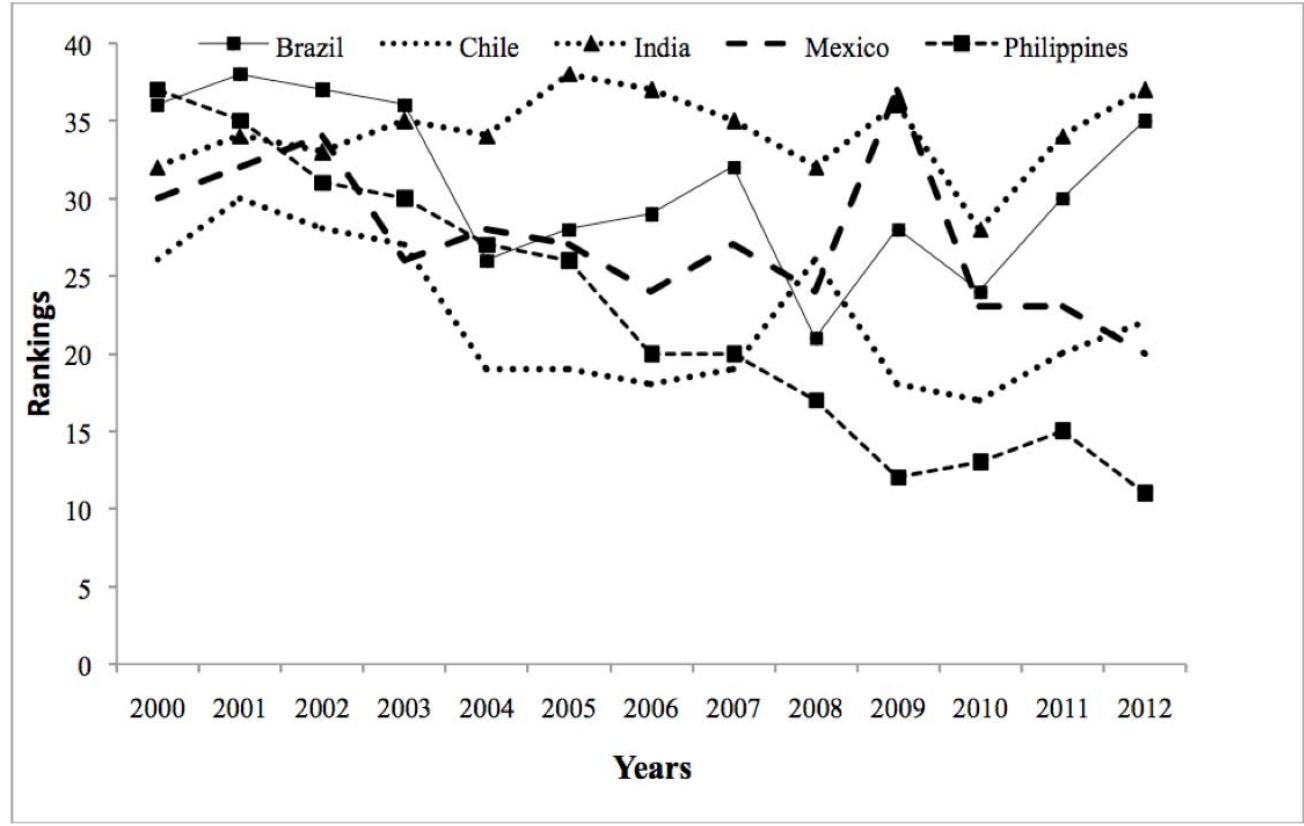

Figure 3: Rankings of Some Developing Economies over the Years.

The results also clearly bring out the effect of the 2007 financial and economic crisis on the change in relative rankings of countries. To an extent, they also point to the worst affected countries as well as those which remained relatively less affected notwithstanding any temporary growth setbacks or setbacks in the CAB or government balances.

Table 3 shows the country-specific distribution of the status of rankings classified as $A, B, C$, and D. It is observed that Sweden and Singapore top the list with a maximum number of $A$ (highest ranking grade) closely followed by Switzerland, Malaysia, Luxembourg, and Hong Kong (each having a frequency of 12), Taiwan and Netherlands (having a frequency of 11). The worst situation occurs with Greece, Poland, Portugal, Romania, and Turkey, each having a frequency of 13 for the category $D$ (the worst gradation). India follows with a frequency of 12 for the category $D$. The US has a frequency of 6 for the category $C$ and 7 for the category $\mathrm{D}$, whereas, the UK performs slightly better with a frequency of 10 for the category $\mathrm{C}$.

The CA Bi-Plot (Figure 4) which is a graphical summarisation of Table $\mathbf{3}$ shows the clustering pattern of the countries around the nodes (A, B, C, D). It is quite evident from Figure 4 that several of the Asian economies, particularly the ASEAN countries mostly belong to the cluster $B$ and some in $A$. On the other hand, several developed economies including the US, UK, core EU economies (excluding Germany) and emerging Latin American economies fall in the cluster
$\mathrm{C}$, while many of the emerging European economies fall in cluster $D$.

It would be observed (Figure 4) that the majority of the inertia is explained by the first two axes, the third dimension explaining the rest. The relative contributions of each cell to the total inertia give some indication of the nature of dependency between the spatial locations and the status of rankings ${ }^{34}$. The implication (of the above) is that if the year-wise country rankings are classified as above, $81 \%$ of the total inertia of Table 3 can be explained in a twodimensional graphical plot (CA Bi-Plot) which effectively gives an overall assessment (in terms of the said categorization viz., A, B, C, D) of the macroeconomic performances of the countries for the period 2000-2012.

For the sake of comparison, we also construct the same composite measure of economic performance, assigning equal weights to all attributes, in place of entropy weights. As expected there are some discrepancies in the rankings derived by these two different weighting schemes. For example, in the postcrisis period, for the US and the UK, the rankings based on the entropy weights are better, compared to those based on equal weights ${ }^{35}$. It would be an

\footnotetext{
${ }^{34}$ The detailed output is not reported here.

${ }^{35}$ The US and the UK, in fact have shown stronger recovery in the year 2013 and early 2014, reflecting improved macroeconomic fundamentals. As the overall discrepancy (between the two sets of rankings) is found to be low, we do not report the results due to lack of space.
} 
Table 3: Distribution of Status of Rankings Across the Countries

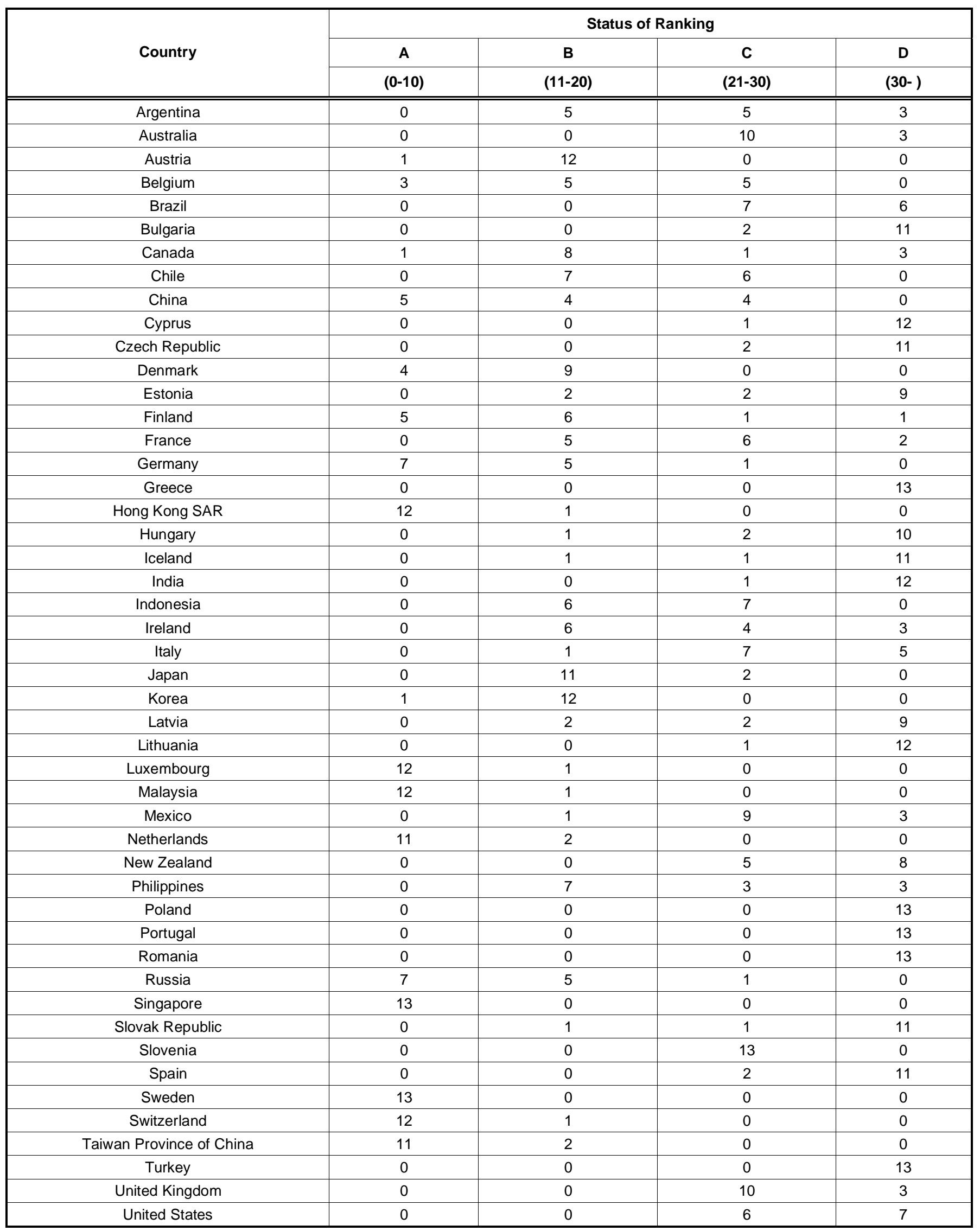




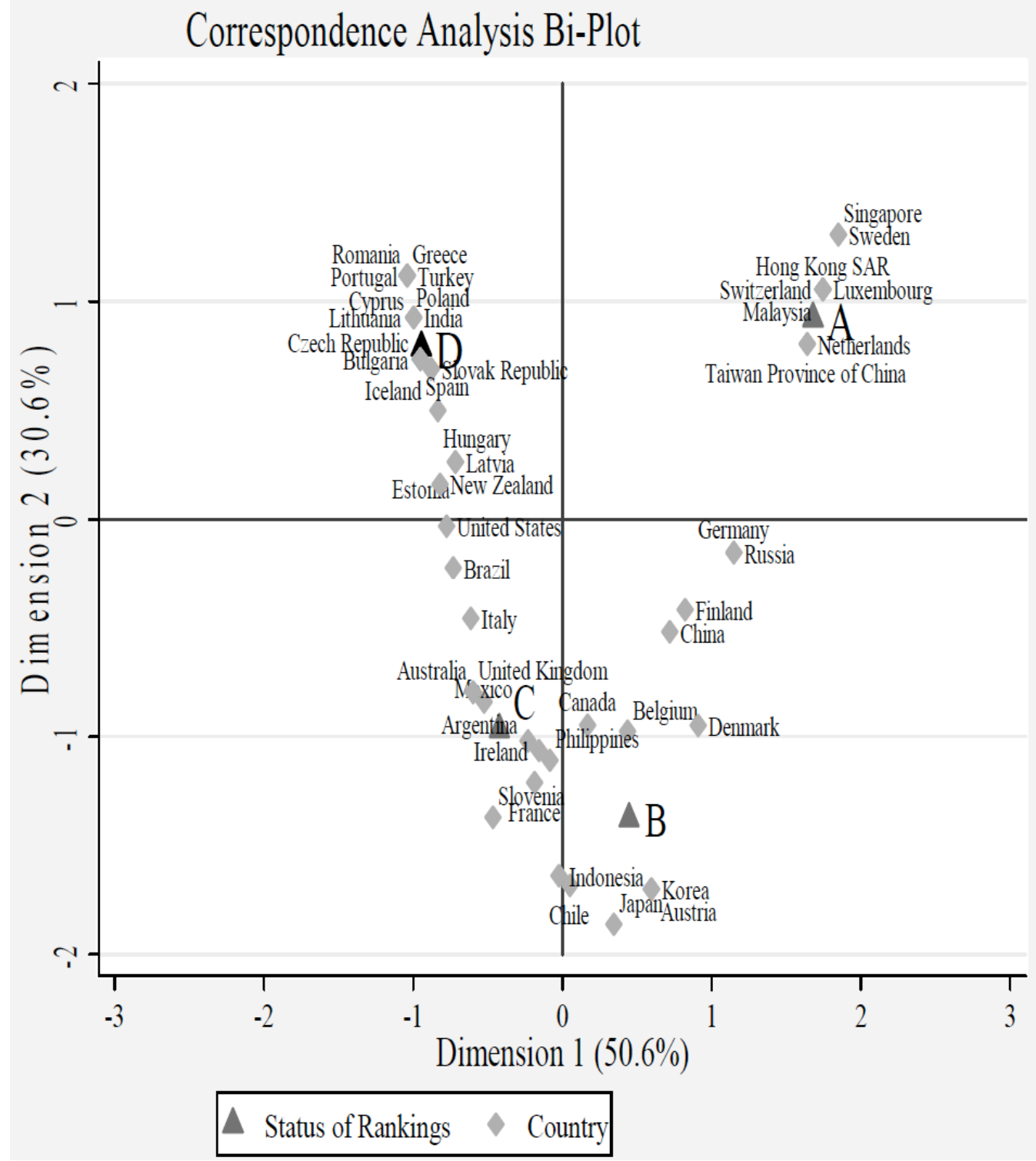

Figure 4: Correspondence Analysis Bi-plot of Status of Rankings vis-à-vis their Spatial Locations.

interesting exercise to perform a simulation exercise by varying the weights arbitrarily between zero and one (also using subsets of data and alternative weighting schemes) so as to make any unambiguous comparison between the country rankings and checking for the robustness of the proposed indicators ${ }^{36}$.

\section{CONCLUSION}

This paper presents a macroeconomic performance index which is designed to summarise in a single statistic a number of macroeconomic indicators. This allows a parsimonious representation of a variety of different facets of macroeconomic performance and its

\footnotetext{
${ }^{36}$ This is however outside the scope of present paper.
}

comparison across countries. The distinctive features of the indicator relate to the domains covered, the normalisation methodology used, and the weights used for aggregation. The first part of the analyses presents the methodology of arriving at the performance scores and the country rankings in each year according to those scores. In the second part the rankings are summarised in terms of measures which together depict the degree of stability or disarray in country-wise rankings over the years. Statistical analysis of the yearwise country rankings based on the composite scores is what constitutes the third part of our analysis. By applying proper statistical techniques, the paper has sought to compare the relative positions of countries over the years. The extent of disarray between the year-wise positions has been summarized by what are respectively known in the literature as the $O, N F r, G$ 
and $M$ measures. The analytical technique of Correspondence Analysis (CA) for providing a graphical display of the status of rankings elegantly summarizes the cross-sectional variability in the relative positions of the countries by mapping them in a two dimensional "biplot" (Greenacre 1993).

The simple macroeconomic performance indicators in common use, viz., the Okun index and the Calmfors index, consider only two variables tacitly assuming that the policy makers accord the same priority to each policy aim, whereas on the contrary it is more realistic to assume that different weights will be attached to different policy goals. Lovell, Pastor, and Turner (1995) and Moesen and Cherchye (1998), for instance, rely on four macroeconomic variables and a variant of linear programming techniques to evaluate the performance scores. The paper includes budget balance and percapita GDP as additional variables and applies the concept of TOPSIS methodology, which is a variant of MCDM technique. This is surely an improvement over the existing indices in the sense that Okun index and the Calmfors index turn out to be special cases of our proposed index. Selection of additional variables (for constructing the macro performance function) is simply contingent on fulfilling the twin requirement of theoretical justification and prior assumption of monotonicity.

By handling a large data set of major countries of the world spanning a significant period, the paper has made an overview of the cross-sectional as well as temporal variations in the status of rankings. The results clearly show that country rankings can vary quite sharply over different indicators considered, and hence underlines the need for this kind of a synthetic composite indicator to serve as a summary statistic, facilitating easy cross-country and inter-temporal comparisons of macroeconomic performance, particularly, where the various existing macroeconomic indicators send conflicting signals. The important observations are that country rankings based on overall macroeconomic performances differ quite significantly from those based on measures traditionally relied on, like GDP growth rates or per capita GDP and that relative rankings for a country may change quite drastically over the years, because of deterioration in certain macroeconomic indicators, even though the country may persistently register a high rate of growth. We are able to identify countries which have performed consistently over time and those whose performances have deteriorated sharply during the post-crisis years. For example, EU countries now exhibit lower rankings as they have adopted severe austerity measures for structural adjustments, which have affected output and employment in those countries. However, the reforms should reflect in the overall rankings in a few years time, as exhibited by the Asian economies in this study; the Asian economies cluster in the higher ranking group with stronger government balances consequent on the structural reforms undertaken in the post-Asian crisis period and no sharp deterioration in other indicators. The relative strength of some of the richer economies like Singapore, Hong Kong, Switzerland, Sweden, and oil exporters like Russia are also easily identified from the summary clustering of country performances ${ }^{37}$. The estimated summary statistics for the degree of stability or disarray experienced in various years, according to our ranking methodology, show that the between 2007 and 2009 the measures of disarray attain their highest values closely followed by the period between 2011 and 2012, which correspond to the peak crisis years.

The usual caveats and policy recommendations apply for this study. Of course, a single indicator, without necessarily parting with valuable data and hence obscuring some essential information, cannot incorporate all the relevant information concerning the performance of an economy. Even so, a single metric is admittedly easier to comprehend and can greatly aid comparison between countries. A comparable composite ranking index usually plays an important role in alerting the government, policy makers and international aid-givers or investors, and force policy makers to delve deeper into the component attributes and structural problems related to those ${ }^{38}$. Policy makers may compare rankings, based on such measures like the one computed here, with similar groups of countries, to better understand their positions. The analyses based on the performance scores help to clearly understand the effect of the recent global financial and economic crisis on the overall macroeconomic performance of different countries. To this end, the paper has an enormous potential from the viewpoint of a policy prescription. This is true insofar as the rankings can subsequently

\footnotetext{
${ }^{37}$ That the ultimate ranking is dominated by rich countries like Singapore, Luxembourg, Switzerland etc could apparently be due to the nature of weighting methodology used, i.e., using essentially the variations across the observation units as weights; as the greatest variation is found for the variable per capita GDP. We note that the use of an equal weighting scheme has in fact kept the positions of these economies more or less the same (also see Footnote 29).

${ }^{38}$ Tools like path analysis, Bayesian networks and structural equation modeling may be quite useful here to unearth further the relationship between the composite and its constituents.
} 
be analyzed in a proper exploratory framework by associating the change in the relative positions of countries over time with certain explanatory variables ${ }^{39}$. It would be an interesting exercise to directly compare the (composite) scores over the years probably following a dynamic version of present methodology. Analysis of the scores alongside the inherent vulnerability and resilience indices of the countries would lend to better policy prescriptions.

\section{REFERENCES}

Aiginger, Karl. 2011. "Why Performance Differed Across Countries in the Recent Crisis : How Country Performance in the Recent Crisis Depended on Pre-crisis Conditions." WIFO Working Papers 387.

Bar-llan, J, M Levene, and A Lin. 2007. "Some Measures for Comparing Citation Databases." Journal of Informetrics 1:26-34 http://dx.doi.org/10.1016/j.joi.2006.08.001

Bar-Ilan, Judit, Mazlita Mat-Hassan, and Mark Levene. 2006. "Methods for Comparing Rankings of Search Engine Results." Computer Networks 50:1448-1463. http://dx.doi.org/10.1016/j.comnet.2005.10.020

Barro, Barro J. and David B. Gordon. 1983. "A Positive Theory of Monetary Policy in a Natural Rate Model." Journal of Political Economy 91(4):589-610. http://dx.doi.org/10.1086/261167

Basu, Kaushik, Supriyo De, Rangeet Ghosh, and Shweta. 2011. "The Evolving Dynamics of Global Economic Power in the PostCrisis World: Revelations from a New Index of Government Economic Power." Ministry of Finance, Government of India.

Bech, Eric J. 2004. "Simple Correspondence Analysis: A Bibliographic Review." International Statistical Review 72(2):257-284.

Blanchard, Oliver J. and Stanley Fischer. 1989. Lectures on Macroeconomics. MIT Press.

Burda, Michael C. and Charles Wyplosz. 1993. Macroeconomics : a European Text. Oxford: Oxford University Press.

Calmfors, L and J Driffill. 1988. "Bargaining Structure, Corporatism and Macroeconomic Performance." Economic Policy 6:1361. http://dx.doi.org/10.2307/1344503

Clark, J D., J E. Dunn, and K G. Smith. 1993. "A Multivariate Model of Female Black Bear Habitat Use for a Geographic Information System." Journal of Wildlife Management 57:519-526. http://dx.doi.org/10.2307/3809276

Crockett, $\mathrm{A}$ and $\mathrm{M}$ Goldstein. 1987. "Indicators of Policies and Economic Performance. Strengthening the International Monetary System: Exchange Rates,Surveillance and Objective Indicators." IMF Occasional Papers 50.

Deng, J L. 1989. "Introduction to the Grey System Theory." J Grey Syst 1:1-24.

Deng, Hepu, Chung-Hsing Yeh, and Robert J. Willis. 2000. "InterCompany Comparison Using Modified TOPSIS with Objective Weights." Computers \& Operations Research 27:963-973. http://dx.doi.org/10.1016/S0305-0548(99)00069-6

\footnotetext{
${ }^{39}$ These explanatory variables might include the fiscal policy of the government, the monetary policy stance of the central bank, the bureaucratic structures, the environmental endowments and infrastructural facilities, openness of the economy, as well as, financial variables like the growth of savings and credit etc. See in this context a recent work by (Aiginger 2011).
}

Denhart, Matthew and Amity Shales. 2012. "Deflation and the Misery Index." George W Bush Foundation, February 22.

Diaconis, P and R L. Graham. 1977. "Spearman's Footrule as a Measure of Disarray." Journal of the Royal Statistical Society, Series B (Methodological) 39:262-268.

Dwork, Cynthia, Ravi Kumar, Moni Naor, and D Sivakumar. 2001. "Rank Aggregation Revisited." (http://cs.brown.edu/courses/ csci2531/papers/rank2.pdf).

Fagin, R, R Kumar, and D Sivakumar. 2003. "Comparing Top K Lists." SIAM Journal on Discrete Mathematics 17(1):134-160. http://dx.doi.org/10.1137/S0895480102412856

Farber, Oren and Ronen Kadmon. 2003. "Assessment of Alternative Approaches for Bioclimatic Modeling with Special Emphasis on the Mahalanobis Distance." Ecological Modelling 160:115130. http://dx.doi.org/10.1016/S0304-3800(02)00327-7

Golan, Amos. 2006. "Information and Entropy Econometrics -A Review and Synthesis." Foundations and Trends in Econometrics 2:1-145. http://dx.doi.org/10.1561/0800000004

Graf, Hans G. 2002. Economic Forecasting for Management: Possibilities and Limitations. Praeger.

Greenacre, M J. 1984. Theory and Applications of Correspondence Analysis. London: Academic Press.

Greenacre, Michael J. 1993. "Biplots in Correspondence Analysis." Journal of Applied Statistics 20(2):251-269. http://dx.doi.org/10.1080/02664769300000021

Greenacre, Michael. 2002. "The Use of Correspondence Analysis in the Exploration of Health Survey Data." Fundación BBVA.

Hall, Robert E. and John B. Taylor. 1997. Macro Economics. W.W. Norton \& Company.

Hoffman, Donna L. and George R. Franke. 1986. "Correspondence Analysis: Graphical Representation of Categorical Data in Marketing Research." Journal of Marketing Research 23(3):213-227.

http://dx.doi.org/10.2307/3151480

Hwang, C L. and K Yoon. 1981. Multiple Attribute Decision Making: Methods and Applications. Berlin: Springer-Verlag. http://dx.doi.org/10.1007/978-3-642-48318-9

Jahanshahloo, G R., F Hosseinzadeh, and M L. Izadikhah. 2006. "An Algorithmic Method to extend TOPSIS for Decision Making Problem with Interval Data." Applied Mathematics and Computation 175:1375-1384. http://dx.doi.org/10.1016/j.amc.2005.08.048

Kendall, M.G. 1972. "The History and Future of Statistics." Pp. 193 210 in Statistical Papers in Honor of George W. Snedecor. Ames, lowa: The lowa State University Press.

Koopmans, T C. 1951. "An Analysis of Production as an Efficient Combination of Activities." in Activity Analysis of Production and Allocation. Jhon Wiley and Sons, Inc.

Legendre, P and L Legendre. 1998. Numerical Ecology. Amsterdam: Elsevier.

Lertprapai, Satinee. 2013. "Review: Multiple Criteria Decision Making Method with Applications." International mathematical Forum 8(7):347-355.

Lovell, C.A. K., Jesus T. Pastor, and Judi A. Turner. 1995 "Measuring Macroeconomic Performance in the OECD: A Comparison of European and Non-European Countries." European Journal of Operational Research 87(3):507-518. http://dx.doi.org/10.1016/0377-2217(95)00226-X

Maasoumi, E. 1993. "A Compendium to Information Theory in Economics and Econometrics." Econometric Reviews 12(2):137-181. http://dx.doi.org/10.1080/07474939308800260

Mahalanobis, P C. 1936. "On the Generalised Distance in Statistics." (www.new1.dli.ernet.in/data1/upload/insa/INSA 1/20006193 -49.pdf). 
Moesen, Wim and Laurens Cherchye. 1998. "The Macroeconomic Performance of Nations: Measurement and Perception." (http://www.econ.kuleuven.be/eng/ew/discussionpapers/Dps 98/Dps9822.pdf).

Nayyar, Deepak. 2011. "Rethinking Macroeconomic Policies for Development." Brazilian Journal of Political Economy 31(3):339-351.

Okun, Arthur M. 1970. Political Economy Of Prosperity. W. W. Norton and Company, Inc.

Okun, Arthur M. 1978. Curing Chronic Inflation. Brookings Institution.

Okun, Arthur M. 1981. Prices and Quantities: A Macroeconomic Analysis. Brookings Institution Press.

Opricovic, S and G H. Tzend. 2004. "Compromise Solution by MCDM methods: a Comparative Analysis of VIKOR and TOPSIS." European Journal of Operations Research 156:445-455. http://dx.doi.org/10.1016/S0377-2217(03)00020-1

Schmitt-Grohe, Stephanie and Martin Uribe. 2010. "The Optimal Rate of Inflation." National Bureau of Economic Research Working Paper 16054.

Sinclair, Peter. 2003. "The Optimal Rate of Inflation: An Academic Perspective." Bank of England Quarterly Bulletin.

Sleigh, J W., E Olofsen, A Dahan, J D. Goede, and A Steyn-Ross. 2001. "Entropies of The EEG: The Effects Of General Anaesthesia.".
Socorro García-Cascales, M and M Teresa Lamata. 2012. "On Rank Reversal and TOPSIS Method." Mathematical and Computer Modelling 56(5-6):123-132. http://dx.doi.org/10.1016/j.mcm.2011.12.022

Stiglitz, Joseph and Amartya Sen. 2009. "Report by the Commission on the Measurement of Economic Performance and Social Progress." (http://www.stiglitz-sen-fitoussi.fr.).

Stiglitz, J, A Sen, and J Fitoussi. 2009. "The Measurement of Economic Performance and Social Progress Revisited: Reflections and Overview." Commission on the Measurement of Economic Performance and Social Progress.

Tella, Rafael D., Robert J. Macculloch, and Andrew J. Oswald. 2001. "Preferences over Inflation and Unemployment: Evidence from Surveys of Happiness." American Economic Review 91(1):335-341. http://dx.doi.org/10.1257/aer.91.1.335

Triantaphyllou, Evangelos. 2000. Multi-Criteria Decision Making Methods: A Comparative Study. Springer. http://dx.doi.org/10.1007/978-1-4757-3157-6

Welsch, Heinz. 2011. "The Magic Triangle of Macroeconomics: How Do European Countries Score?" Oxford Economic Papers 63(1):71-93. http://dx.doi.org/10.1093/oep/gpq020

Zeleny, M. 1982. Multiple Criteria Decision Making. New York: McGraw-hill.

\section{DOI: http://dx.doi.org/10.6000/1929-7092.2015.04.05}

(C) 2015 Chattopadhyay and Bose; Licensee Lifescience Global.

This is an open access article licensed under the terms of the Creative Commons Attribution Non-Commercial License (http://creativecommons.org/licenses/by-nc/3.0/) which permits unrestricted, non-commercial use, distribution and reproduction in any medium, provided the work is properly cited. 